\title{
Abdominal muscle fatigue following exercise in chronic obstructive pulmonary disease
}

\author{
Nicholas S Hopkinson ${ }^{1 *}$, Mark J Dayer ${ }^{1}$, John Moxham², Michael I Polkey ${ }^{1}$
}

\begin{abstract}
Background: In patients with chronic obstructive pulmonary disease, a restriction on maximum ventilatory capacity contributes to exercise limitation. It has been demonstrated that the diaphragm in COPD is relatively protected from fatigue during exercise. Because of expiratory flow limitation the abdominal muscles are activated early during exercise in COPD. This adds significantly to the work of breathing and may therefore contribute to exercise limitation. In healthy subjects, prior expiratory muscle fatigue has been shown itself to contribute to the development of quadriceps fatigue. It is not known whether fatigue of the abdominal muscles occurs during exercise in COPD.
\end{abstract}

Methods: Twitch gastric pressure (TwT1OPga), elicited by magnetic stimulation over the $10^{\text {th }}$ thoracic vertebra and twitch transdiaphragmatic pressure (TwPdi), elicited by bilateral anterolateral magnetic phrenic nerve stimulation were measured before and after symptom-limited, incremental cycle ergometry in patients with COPD.

Results: Twenty-three COPD patients, with a mean (SD) FEV 1 40.8(23.1)\% predicted, achieved a mean peak workload of 53.5(15.9) W. Following exercise, TwT 10 Pga fell from 51.3(27.1) $\mathrm{cmH}_{2} \mathrm{O}$ to $47.4(25.2) \mathrm{cmH}_{2} \mathrm{O}(\mathrm{p}=0.011)$. TwPdi did not change significantly; pre 17.0(6.4) $\mathrm{cmH}_{2} \mathrm{O}$ post $17.5(5.9) \mathrm{cmH}_{2} \mathrm{O}(\mathrm{p}=0.7)$. Fatiguers, defined as having a fall TwT10Pga $\geq 10 \%$ had significantly worse lung gas transfer, but did not differ in other exercise parameters.

Conclusions: In patients with COPD, abdominal muscle but not diaphragm fatigue develops following symptom limited incremental cycle ergometry. Further work is needed to establish whether abdominal muscle fatigue is relevant to exercise limitation in COPD, perhaps indirectly through an effect on quadriceps fatigability.

\section{Background}

Chronic obstructive pulmonary disease (COPD) is characterized by damage to airways and lung parenchyma, which leads to expiratory flow limitation. As expiratory flow is volume-dependent, increased ventilatory demands are met by an increase in operating lung volumes. This dynamic hyperinflation places both elastic and resistive loads on the respiratory muscles and increases the disparity between neural drive and mechanical output [1]. There has been long-standing interest in the role of the respiratory muscles in contributing to ventilatory limitation and task failure, both in health and disease [2,3].

Peripheral muscle fatigue is defined as a reversible loss of the ability to generate force, resulting from activity

\footnotetext{
* Correspondence: n.hopkinson@ic.ac.uk

${ }^{1}$ National Heart and Lung Institute, Imperial College, Royal Brompton Hospital, Fulham Rd, London SW3 6NP, UK
}

under load [2]. The diaphragm is the principal inspiratory muscle and it is possible to induce diaphragm fatigue in healthy subjects through breathing against an inspiratory load or by maximum voluntary ventilation $[4,5]$. Diaphragm fatigue also occurs at high levels of whole body exercise [6-8]. However in COPD, it has been shown that despite the diaphragm being loaded during exercise [9], low frequency fatigue, demonstrated by a persistent fall in response to supramaximal nerve stimulation, does not occur following either treadmill or cycle exercise $[10,11]$. Likewise, maximum voluntary ventilation did not induce diaphragm fatigue in a study of six patients with severe COPD [12]. Moreover, even in patients with COPD who fail a trial of weaning from mechanical ventilation, low frequency diaphragm fatigue was not observed [13]. Taken together, these data suggest that diaphragm fatigue is unlikely to be relevant to exercise limitation in COPD, perhaps because of a 
protective effect of hyperinflation and consequent muscle shortening [14].

During quiet breathing in healthy subjects, expiration is passive, driven largely by lung elastic recoil, but as ventilation increases the abdominal muscles are recruited to increase expiratory flow rate [15]. Few data exist regarding the role of expiratory muscle fatigue, but it has been demonstrated that maximum voluntary ventilation loads the abdominal muscles, slowing their relaxation rate and causing low frequency fatigue to develop $[5,16,17]$. High intensity, whole-body exercise also causes expiratory muscle fatigue to develop in healthy individuals $[18,19]$. In COPD, the abdominal muscles are frequently recruited even during resting breathing [20]. When walking to exhaustion, inspiratory work of breathing in COPD rises rapidly but then plateaus, whereas expiratory muscle recruitment and pressure time product continue to rise [21] and in some patients slowing of the expiratory muscle maximum relaxation rate has been noted [22].

Low frequency fatigue (LFF) describes the loss of force generated in response to low stimulation frequencies $(10-20 \mathrm{~Hz})$, which are the typical motor neuron firing frequencies during human skeletal muscle activity. LFF in a muscle can be identified by measuring the reduction in the force elicited by a single stimulus applied to a peripheral nerve supplying that muscle, before and after exercise (or other contractile activity), provided the same stimulus is given before and afterwards. A convenient way to do this is to give a stimulus which activates all nerve and muscle fibres (a supramaximal stimulus) [23]. For skeletal muscle LFF is typically assessed 20 minutes after exercise to allow the effects of exercise induced potentiation to wear off [24].

This study was intended to investigate whether the increased loading that the expiratory muscles are subject to during exercise in COPD, would lead to the development of abdominal muscle fatigue, assessed using the technique of magnetic stimulation of the lower thoracic nerve roots.

\section{Methods}

Patients with COPD, defined according to GOLD criteria[25] were recruited from outpatient clinics. Patients were excluded if they had had symptoms suggestive of an acute exacerbation in the previous month. The Research Ethics Committee of The Royal Brompton Hospital approved the study. All patients gave written informed consent. Some of the baseline data from these subjects has been reported previously [26].

Spirometry, plethysmographic lung volumes and gas transfer (Compact Lab System, Jaeger, Germany) as well as arterialized capillary blood gas tensions were measured as described previously [26]. Fat free mass (FFM) was determined using bioelectrical impedance analysis (Bodystat 1500, Bodystat, Isle of Man, UK) and a disease specific regression equation [27].

Following the placement of oesophageal and gastric balloon catheters[28] maximum inspiratory (PImax), expiratory (PEmax) [29], sniff nasal (SNiP), transdiaphragmatic (SnPdi)[30] and cough gastric (CoughPga)[31] pressures were determined. Pressure signals were amplified and passed to a computer running LabView 4.1 software (National Instruments, Austin, Texas, USA),

After performing the volitional tests, subjects remained seated quietly for twenty minutes to depotentiate their respiratory muscles. Diaphragm strength was assessed as the unpotentiated response elicited by bilateral, anterolateral, magnetic phrenic nerve stimulation (TwPdi) at resting end expiration, using a pair of $45 \mathrm{~mm}$ figure of eight coils each powered by a Magstim 200 monopulse unit (Magstim Ltd, Whitland, UK) delivering an output $100 \%$ of maximum with patients seated upright in a straight-backed chair [32].

Abdominal muscle strength was assessed using the gastric pressure response to stimulation, delivered to the nerve roots supplying the abdominal muscles, at the level of the $10^{\text {th }}$ thoracic vertebra ( $\left.\mathrm{Tw}_{10} \mathrm{Pga}\right)$ by a circular coil. Coil position was adjusted to produce the maximal response in gastric pressure. Stimulations were performed at total lung capacity, with the patient seated upright astride the chair. Subjects were instructed to inhale to total lung capacity fully and then relax with a closed glottis. Care was taken to ensure that the subject maintained the same posture and coil position was marked with indelible pen.

The exercise protocol used has been described elsewhere [26]. Briefly, it involved an initial two minute rest period followed by unloaded cycling for $30 \mathrm{sec}-$ onds and then increments of $5 \mathrm{~W}$ every 30 seconds subsequently. A mouthpiece connected to an Oxycon device (Jaeger, Germany) was used for breath-bybreath metabolic measurements of oxygen consumption $\left(\mathrm{VO}_{2}\right)$ and $\mathrm{CO}_{2}$ production $\left(\mathrm{VCO}_{2}\right)$. Subjects performed an inspiratory capacity manoeuvre every minute to assess dynamic hyperinflation. EELV was calculated by subtracting inspiratory capacity from total lung capacity (as the latter does not change during exercise[33,34]). The reason given for stopping was documented.

Following exercise, subjects sat quietly for 20 minutes to depotentiate before the magnetic stimulations were repeated. On both occasions, the phrenic nerve stimulations were performed before the thoracic nerve root stimulations.

\section{Statistical analysis}

Values before and after exercise were compared using paired $t$ tests. Correlations between percent change in 
$\mathrm{TwT}_{10}$ Pga and both baseline parameters and exercise parameters were sought using linear regression analysis. Individuals where the $\mathrm{TwT}_{10}$ Pga fell by $>10 \%$ were defined as 'fatiguers' and compared to 'non-fatiguers' using an appropriate test for paired comparison. Values are expressed as mean (SD) and a $\mathrm{p}$ value of $<0.05$ was taken to be significant.

\section{Results}

Twenty-three COPD patients (17 male) with a mean (SD) $\mathrm{FEV}_{1} 40.8(23.1) \%$ took part in the study. Baseline characteristics and exercise performance are given in
Table 1.10 patients reported that they stopped because of breathlessness, 5 because of leg fatigue and 8 because of a combination of the two. During exercise, significant dynamic hyperinflation occurred, with end expiratory lung volume (EELV) rising from 5.97(1.65) litres to 6.62 (1.95) litres ( $\mathrm{p}<0.0001)$.

Following exercise, $\mathrm{TwT}_{10}$ Pga fell from 51.3(27.1) $\mathrm{cmH}_{2} \mathrm{O}$ to $47.4(25.2) \mathrm{cmH}_{2} \mathrm{O}(\mathrm{p}=0.011)$ (Figure 1). In 8 patients it fell by more than $10 \%$ from baseline. The gastric pressure at which T10 stimulations were administered did not differ significantly; pre 22.3(6.6) $\mathrm{cmH}_{2} \mathrm{O}$ vs post 22.4(7.3) $\mathrm{cmH}_{2} \mathrm{O}$.

Table 1 Participant characteristics and exercise parameters:

\begin{tabular}{|c|c|c|c|c|}
\hline & $\begin{array}{l}\text { Mean(sd) } \\
n=23\end{array}$ & $\begin{array}{l}\text { Non-fatiguers } \\
\mathrm{n}=15\end{array}$ & $\begin{array}{l}\text { Fatiguers } \\
\mathrm{n}=\mathbf{8}\end{array}$ & $\mathbf{P}$ \\
\hline Age (years) & $61.8(25.2)$ & $63.1(8.5)$ & $59.4(12.6)$ & 0.4 \\
\hline Pack years smoked & $50.5(23.3)$ & $54.1(25.6)$ & 43.7(17.6) & 0.3 \\
\hline $\mathrm{BMI}\left(\mathrm{kg} \cdot \mathrm{m}^{-2}\right)$ & $23.3(5.0)$ & $24.1(3.5)$ & $21.7(7.1)$ & 0.3 \\
\hline FFMI $\left(\mathrm{kg} \cdot \mathrm{m}^{-2}\right)$ & $16.1(2.0)$ & $16.3(1.6)$ & $15.5(2.8)$ & 0.4 \\
\hline \multicolumn{5}{|l|}{ Lung function } \\
\hline FEV $1 \%$ predicted & $40.8(23.1)$ & $45.8(25.2)$ & $31.6(15.9)$ & 0.17 \\
\hline FVC \%predicted & $85.1(29.3)$ & $93.1924 .8)$ & 70.1 (11.6) & 0.07 \\
\hline TLC \%predicted & $131.4(17.5)$ & $130.3(16.5)$ & $133.3(20.4)$ & 0.7 \\
\hline $\mathrm{RV} / \mathrm{TLC}$ & $58.2(9.2)$ & $57.5(8.0)$ & $59.6(11.7)$ & 0.6 \\
\hline FRC \%predicted & $182.0(41.2)$ & $177.9(35.5)$ & $189.6(52.4)$ & 0.5 \\
\hline $\mathrm{TLCO}_{\mathrm{c}} \%$ predicted & $39.6(16.4)$ & $45.4(16.3)$ & $30.0(10.9)$ & $0.03^{*}$ \\
\hline $\mathrm{KCO}_{c} \%$ predicted & $45.9(18.7)$ & $51.8(19.0)$ & $34.9(12.9)$ & $0.04^{*}$ \\
\hline $\mathrm{PaCO}_{2}(\mathrm{kPa})$ & $4.9(0.6)$ & $4.7(0.6)$ & $5.2(0.4)$ & 0.06 \\
\hline $\mathrm{PaO}_{2}(\mathrm{kPa})$ & $9.9(1.1)$ & $9.8(1.1)$ & $10.0(1.2)$ & 0.7 \\
\hline \multicolumn{5}{|l|}{ Muscle strength } \\
\hline PImax $\left(\mathrm{cmH}_{2} \mathrm{O}\right)$ & $53.7(21.2)$ & $50.7(18.0)$ & $58.5(26.1)$ & 0.4 \\
\hline PEmax $\left(\mathrm{cmH}_{2} \mathrm{O}\right)$ & $80.9(26.3)$ & $77.5(27.4)$ & $86.4(25.2)$ & 0.5 \\
\hline SnPdi $\left(\mathrm{cmH}_{2} \mathrm{O}\right)$ & $94.2(16.1)$ & $92.7(12.3)$ & $97.0(22.5)$ & 0.6 \\
\hline Cough Pgas $\left(\mathrm{cmH}_{2} \mathrm{O}\right)$ & $241.0(60.3)$ & $242.7(66.3)$ & $237.6(49.5)$ & 0.9 \\
\hline TwT10Pgas $\left(\mathrm{cmH}_{2} \mathrm{O}\right)$ & $51.3(27.1)$ & $47.7(24.5)$ & $58.1(31.8)$ & 0.4 \\
\hline TwPdi $\left(\mathrm{cmH}_{2} \mathrm{O}\right)$ & $17.0(6.4)$ & $17.4(6.2)$ & $16.2(6.9)$ & 0.7 \\
\hline QMVC (kg) & $32.3(9.6)$ & $32.1(10.0)$ & $32.6(9.5)$ & 0.9 \\
\hline \multicolumn{5}{|l|}{ Exercise parameters } \\
\hline Peak VO $2\left(\mathrm{ml} \mathrm{kg}^{-1} / \mathrm{min}\right)$ & $11.5(3.3)$ & $12.1(3.3)$ & $10.4(3.0)$ & 0.2 \\
\hline Peak VCO $2\left(\mathrm{ml} \mathrm{kg}^{-1} / \mathrm{min}\right)$ & $11.1(3.9)$ & $11.6(4.2)$ & $10.1(3.2)$ & 0.4 \\
\hline Peak workload (W) & 53.5(15.9) & $57.0(16.7)$ & $47.0(13.0)$ & 0.16 \\
\hline Peak VE (I/min) & $29.9(9.2)$ & $32.3(9.4)$ & $25.5(7.6)$ & 0.09 \\
\hline Rest EELV (I) & $5.97(1.65)$ & $5.84(1.5)$ & $6.22(2.0)$ & 0.6 \\
\hline Peak EELV (I) & $6.62(1.95)$ & $6.46(1.9)$ & $6.91(1.1)$ & 0.6 \\
\hline$\triangle \mathrm{EELV}(\%)$ & $10.4(8.2)$ & $9.7(6.1)$ & $11.6(11.6)$ & 0.7 \\
\hline$\triangle$ TwPdi (\%) & 2.2. (15.9) & $+7.7(14.9)$ & $-7.9(13.2)$ & $0.02^{*}$ \\
\hline$\triangle$ TwT10Pgas (\%) & $-7.2(15.6)$ & $0.3(10.8)$ & $-21.3(13.5)$ & $<0.001^{*}$ \\
\hline
\end{tabular}

BMI body mass index, FFMI fat free mass index, FEV ${ }_{1}$ forced expiratory volume in one second, FVC forced vital capacity, TLC total lung capacity, RV residual volume, $\mathrm{FRC}$ functional residual capacity, $\mathrm{TLCO}_{\mathrm{c}}$ carbon monoxide transfer factor corrected for haemoglobin, $\mathrm{KcO}_{\mathrm{c}}$ carbon monoxide transfer coefficient corrected for haemoglobin, $\mathrm{PaO}_{2}$ partial pressure of oxygen, $\mathrm{PaCO}_{2}$ partial pressure of carbon dioxide, PImax maximum inspiratory pressure, $\mathrm{PEmax}$ maximum expiratory pressure, SnPdi sniff transdiaphragmatic pressure, Pgas gastric pressure, TwPdi twitch transdiaphragmatic pressure, QMVC quadriceps maximum voluntary contraction force, $\mathrm{VO}_{2}$ oxygen consumption, $\mathrm{VCO}_{2}$ carbon dioxide production, $\mathrm{EELV}$ end expiratory lung volume 


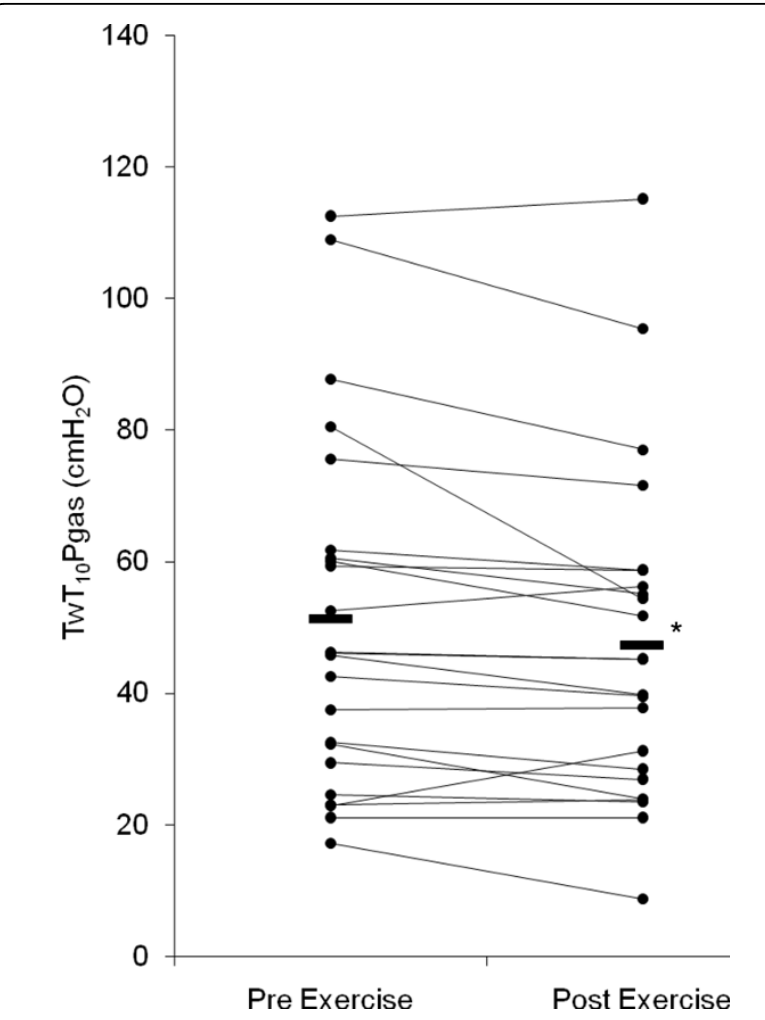

Figure 1 Twitch gastric pressure before and after exercise Twitch T10 gastric pressure fell significantly following symptom limited cycle ergometry in 23 patients with COPD. $\left({ }^{*} p=0.011\right)$.

There was a weak inverse correlation between the percent fall in $\mathrm{TwT}_{10}$ Pga and $\mathrm{Kco}_{\mathrm{c}}\left(\mathrm{r}^{2} 0.19 \mathrm{p}=0.04\right)$ but change in $\mathrm{TwT}_{10}$ Pga did not correlate with any other baseline parameter. There was also no correlation with parameters measured during exercise including $\dot{\mathrm{V}}_{\mathrm{CO}_{2}}$, $\dot{\mathrm{V}}_{\mathrm{O}_{2}}$, VE, exercise duration, the degree of dynamic hyperinflation that occurred or the reason for stopping exercise.

Subjects with at least a $10 \%$ fall in $\mathrm{TwT}_{10}$ Pga 'fatiguers' were compared with 'non-fatiguers' (Table 1). Gas transfer was significantly lower in the fatiguing group and lung volumes tended to be worse, though the latter differences were not statistically significant. There was no difference between the two groups in terms of exercise parameters, in dynamic lung volume changes or reasons given for stopping.

There was no significant change in TwPdi following exercise - pre 17.0(6.4) $\mathrm{cmH}_{2} \mathrm{O}$ post 17.5(5.9) $\mathrm{cmH}_{2} \mathrm{O}(\mathrm{p}$ $=0.7$. .

Portable equipment needed to perform the invasive measurements during exercise in the exercise lab was not available when some of the subjects were studied. Oesophageal and gastric pressure measurements during exercise were therefore available in 14 subjects, 6 of whom were fatiguers. In this subgroup, gastric pressure time product increased from 134 (160) $\mathrm{cmH}_{2} \mathrm{O}$.sec.min ${ }^{-1}$ at rest to $555(332) \mathrm{cmH}_{2} \mathrm{O} . \mathrm{sec}$. min ${ }^{-1}$ during the last 30 seconds of exercise $(\mathrm{p}<0.0001)$. Neither absolute PTPga, nor change in PTPga, nor the amplitude of the gastric pressure swing with expiration was associated with change in $\mathrm{TwT}_{10}$ Pga.

\section{Discussion}

We found that in patients with COPD, twitch gastric pressure fell following symptom-limited cycle ergometry, whereas twitch transdiaphragmatic pressure did not, indicating that low frequency fatigue had developed in the abdominal muscles but not the diaphragm. The mean change was small and was not associated with any parameter measured during exercise. Abdominal muscle fatigue was more likely to occur in patients with the lowest gas transfer.

\section{Significance of findings}

Our results suggest that fatigue of the abdominal muscles, the main muscles of expiration, can develop in COPD patients exercising to exhaustion on a cycle ergometer. Although not measured during exercise, the severity of our patients' COPD, judged by $\mathrm{FEV}_{1}$, and the shape of their flow volume curves makes the likelihood of their having flow limitation extremely high. Accepting this assumption, the presence of expiratory flow limitation means that increased abdominal muscle recruitment during exercise would not increase expiratory flow rates and as such the activation may to some extent be 'futile', which is not the case in normal subjects, in whom the distinction into inspiratory and expiratory is not absolute. During exercise, at least in normal subjects, the expiratory muscles act as accessory muscles of inspiration by reducing end expiratory lung volume, so that the diaphragm is lengthened to an optimum position. Thus their relaxation assists the diaphragm during inspiration, possibly allowing high levels of ventilation to be sustained for a longer period [35].

Abdominal muscle fatigue could be relevant to exercise performance in COPD either because it limits ventilation directly, or because of indirect effects. There is evidence in healthy subjects that high intensity exercise produces expiratory muscle fatigue $[18,19]$ and that fatigue of the expiratory muscles can influence exercise performance [36,37]. Moreover in patients with a congenital weakness of abdominal muscles, the prune belly syndrome [38], peak exercise performance is reduced. Suzuki et al found that fatiguing the abdominal muscles with sit ups to task failure, caused a reduction in both PEmax and $\mathrm{TwT}_{10}$ Pga, but did not reduce subsequent performance of MVV, which argues against a direct effect on ventilatory capacity as a mechanism of exercise limitation [39].

Fatigue of the expiratory muscles has been shown to increase sympathetic vasoconstrictor outflow to 
peripheral muscles [40], which could promote limb muscle fatigue. Consistent with this, a greater degree of quadriceps fatigue occurred after exercise in subjects cycling having first undergone an expiratory muscle fatiguing protocol, than following an equivalent exercise duration when not first fatigued [36]. Interestingly, in that study subjects exercising with prior expiratory muscle fatigue experienced both more dyspnoea and greater leg discomfort. In the present study quadriceps fatigue was not measured, so we cannot comment on any possible relationship between abdominal and limb muscle fatigue in COPD though this would clearly be an interesting area for future work.

The fall in $\mathrm{TwT}_{10}$ Pga was smaller than that observed following exhaustive exercise in healthy subjects exercising to exhaustion $[18,19]$. This may be because of differences in the exercise protocol (incremental vs. endurance) or in the symptoms limiting exercise.

The observation that 'fatiguers' had worse lung function parameters is interesting. This was not reflected in differences in the symptoms limiting exercise, the degree of dynamic hyperinflation that occurred or in oxygenation during exercise. Gas transfer has been associated with impairment of fat free mass [41] in COPD but neither this nor quadriceps strength differed between the two groups. We also note that this group had a mean $7.9 \%$ fall in TwPdi, while the nonfatiguers had a mean $7.7 \%$ increase (making a mean difference of $15.6 \%$ compared with $21.6 \%$ for TwPga). This relationship was not significant when the two parameters were considered as continuous variables so should be treated with caution. It does raise the possibility that a sub-population of patients with COPD might be particularly sensitive to developing respiratory muscle fatigue during exercise, perhaps because the demands of the contracting quadriceps exert a 'steal' phenomenon from both inspiratory and expiratory muscle groups.

Our findings are consistent with previous work showing that the diaphragm does not fatigue following exercise in COPD [10]. This may be because of muscle adaptations including an increased proportion of type I fatigue resistant muscle fibres, or because muscle shortening due to lung hyperinflation protects against fatigue [42]. Conversely abdominal muscles lengthen during hyperinflation potentially rendering them more susceptible to fatigue, though we saw no relationship between dynamic hyperinflation and the propensity to abdominal muscle fatigue. We are not aware of any data regarding the fibre type of abdominal muscles in COPD (in health the fibre distribution is similar to the quadriceps [43]), but their strength is preserved in the condition as evidenced by normal cough gastric pressures [31].

\section{Methodological issues}

A key task was to ensure that the conformation of the abdomen was similar before and after exercise. Care was taken to ensure that the stimuli were delivered in the same way, with the coil and patients in the same position. We did not repeat measurements of lung volumes following exercise, but it is known that total lung capacity does not change significantly either during or after exercise in patients with COPD [34,44]. The observation that the gastric pressure at which stimulations were delivered was the same pre- and post-exercise also suggests that the conformation of the abdominal compartment was similar in both conditions. This was also the case for end-expiratory oesophageal pressure when phrenic nerve stimulations were delivered. The absence of change in TwPdi or TwPoes also argues against significant lung volume change at the point of measurement, since these variables are known to be sensitive to lung volume change [45].

For reasons of tolerability we did not formally assess the supramaximality of the magnetic stimulation in either the phrenic or thoracic nerve root stimulation. In the case of magnetic phrenic nerve stimulation this has been demonstrated in numerous previous studies $[32,46-50]$. For thoracic nerve root stimulation, a plateau in $\mathrm{M}$-wave response has been observed by a number of authors $[18,19,36]$ with no change in M-wave occurring after exercise $[16,18,19,36]$, suggesting that any exercise induced fall in $\mathrm{TwT}_{10}$ Pga is due to a reduction in contractility rather than a reduction in electrical transmission.

It is also possible that the extent of fatigue was 'underestimated' because of the use of unpotentiated twitches, as the change in the (larger) potentiated twitches following fatiguing tasks tends to be more pronounced $[51,52]$. However we also note that the recent vogue for using potentiated twitches [51] is predated by the original description of magnetic stimulation techniques in which unpotentiated twitches were universally used (for example $[10,12,23])$, precisely because investigators wished to be confident that true fatigue (rather than a modulating effect of potentiation) had occurred.

Finally, we chose to deliver TwT10 stimulations at TLC rather than FRC in this study, because in pilot work the response was larger, and also because TLC is considered to be a fixed volume in COPD unlike FRC which is known to vary with minute ventilation. We think variance from this source is likely to have been modest, both because the length-tension relationship for the abdominal muscles is considerably less important than for the diaphragm [53] and because our COPD patients, by virtue of resting hyperinflation (Table 1) had an FRC which was markedly closer to TLC than would be observed in healthy subjects. Other studies 
have used stimulation at FRC, which precludes direct comparison of the amplitude of the twitches [16-18]. Although we did not study repeatability in this population, the reproducibility of response to TwT10 stimulation has been confirmed in healthy subjects $[16,18,36]$.

\section{Conclusions}

Expiratory muscle fatigue occurs in patients with COPD exercising to exhaustion, but it does not necessarily follow that this fatigue is relevant to exercise performance in COPD. If this were to be the case, it may well be through increasing quadriceps fatigability through enhanced sympathetic activation, rather than via a direct effect on ventilatory capacity. Further studies are needed to establish whether expiratory muscle fatigue has an impact on quadriceps fatigability in this population.

\section{Acknowledgements \\ The work was performed at The Royal Brompton Hospital. This study was funded by The Wellcome Trust (G062414) and The British Heart Foundation (PG/2001042). It was supported by the NIHR Respiratory Disease Biomedical Research Unit at the Royal Brompton Hospital and Harefield NHS Foundation Trust and Imperial College London. \\ Author details \\ ${ }^{1}$ National Heart and Lung Institute, Imperial College, Royal Brompton Hospital, Fulham Rd, London SW3 6NP, UK. 'King's College Hospital, Denmark Hill, London SE5 9RS, UK.}

\section{Authors' contributions}

$\mathrm{NSH}, \mathrm{MD}, \mathrm{JM}$ and MIP conceived the study; NSH and MD performed the study measurements and the data analysis. NSH wrote the first draft of the paper to which all authors subsequently made contributions. All authors read and approved the final manuscript.

\section{Competing interests}

The authors declare that they have no competing interests.

Received: 13 November 2009

Accepted: 4 February 2010 Published: 4 February 2010

\section{References}

1. Calverley PM, Koulouris NG: Flow limitation and dynamic hyperinflation: key concepts in modern respiratory physiology. Eur Respir J 2005, 25:186-199.

2. NHLBI Workshop: Respiratory muscle fatigue. Report of the Respiratory Muscle Fatigue Workshop Group. Am Rev Respir Dis 1990, 142:474-480.

3. American Thoracic Society/European Respiratory Society: Skeletal muscle dysfunction in chronic obstructive pulmonary disease. A statement of the American Thoracic Society and European Respiratory Society. Am J Respir Crit Care Med 1999, 159:S1-40.

4. Hamnegard CH, Wragg S, Kyroussis D, Mills GH, Polkey Ml, Moran J, Road J, Bake B, Green M, Moxham J: Diaphragm fatigue following maximal ventilation in man. Eur Respir J 1996, 9:241-247.

5. Renggli AS, Verges S, Notter DA, Spengler CM: Development of respiratory muscle contractile fatigue in the course of hyperpnoea. Respir Physiol Neurobiol 2008, 164:366-372.

6. Mador MJ, Magalang UJ, Rodis A, Kufel TJ: Diaphragmatic fatigue after exercise in healthy human subjects. Am Rev Respir Dis 1993, 148:1571-1575

7. Johnson BD, Babcock MA, Suman OE, Dempsey JA: Exercise-induced diaphragmatic fatigue in healthy humans. J Physiol 1993, 460:385-405.
8. Babcock MA, Pegelow DF, Johnson BD, Dempsey JA: Aerobic fitness effects on exercise-induced low-frequency diaphragm fatigue. J Appl Physiol 1996, 81:2156-2164.

9. Kyroussis D, Polkey MI, Keilty SE, Mills GH, Hamnegard CH, Moxham J, Green M: Exhaustive exercise slows inspiratory muscle relaxation rate in chronic obstructive pulmonary disease. Am J Respir Crit Care Med 1996, 153:787-793.

10. Polkey MI, Kyroussis D, Keilty SE, Hamnegard CH, Mills GH, Green M, Moxham J: Exhaustive treadmill exercise does not reduce twitch transdiaphragmatic pressure in patients with COPD. Am J Respir Crit Care Med 1995, 152:959-964.

11. Mador MJ, Kufel TJ, Pineda LA, Sharma GK: Diaphragmatic fatigue and high-intensity exercise in patients with chronic obstructive pulmonary disease. Am J Respir Crit Care Med 2000, 161:118-123.

12. Polkey MI, Kyroussis D, Hamnegard CH, Mills GH, Hughes PD, Green M, Moxham J: Diaphragm performance during maximal voluntary ventilation in chronic obstructive pulmonary disease. Am J Respir Crit Care Med 1997, 155:642-648.

13. Laghi F, Cattapan SE, Jubran A, Parthasarathy S, Warshawsky P, Choi Y-SA, Tobin MJ: Is Weaning Failure Caused by Low-Frequency Fatigue of the Diaphragm?. Am J Respir Crit Care Med 2003, 167:120-127.

14. Clanton TL, Hartman E, Julian MW: Preservation of sustainable inspiratory muscle pressure at increased end-expiratory lung volume. Am Rev Respir Dis 1993, 147:385-391.

15. Campbell EJM, Green JH: The variations in intraabdominal pressure and the activity of the abdominal muscles during breathing; a study in man. J Physiol (Lond) 1953, 122:282-290.

16. Kyroussis D, Mills GH, Polkey Ml, Hamnegard CH, Koulouris N, Green M, Moxham J: Abdominal muscle fatigue after maximal ventilation in humans. J Appl Physiol 1996, 81:1477-1483.

17. Kyroussis D, Mills GH, Polkey MI, Hamnegard CH, Wragg S, Road J, Green M, Moxham J: Effect of maximum ventilation on abdominal muscle relaxation rate. Thorax 1996, 51:510-515.

18. Taylor BJ, How SC, Romer LM: Exercise-induced abdominal muscle fatigue in healthy humans. J Appl Physiol 2006, 100:1554-1562.

19. Verges S, Schulz C, Perret C, Spengler CM: Impaired abdominal muscle contractility after high-intensity exhaustive exercise assessed by magnetic stimulation. Muscle \& Nerve 2006, 34:423-430.

20. Ninane V, Rypens F, Yernault JC, De Troyer A: Abdominal muscle use during breathing in patients with chronic airflow obstruction. Am Rev Respir Dis 1992, 146:16-21.

21. Kyroussis D, Polkey MI, Hamnegard CH, Mills GH, Green M, Moxham J: Respiratory muscle activity in patients with COPD walking to exhaustion with and without pressure support. Eur Respir J 2000, 15:649-655.

22. Kyroussis D, Polkey Ml, Mills GH, Hamnegard CH, Moxham J, Green M: Abominal muscle relaxation rate in patients with COPD walking to exhaustion. Eur Respir J 1995, 8:381.

23. Polkey Ml, Kyroussis D, Hamnegard CH, Mills GH, Green M, Moxham J: Quadriceps strength and fatigue assessed by magnetic stimulation of the femoral nerve in man. Muscle Nerve 1996, 19:549-555.

24. Wragg SD, Hamnegard CH, Road J, Kyroussis D, Moran J, Green M, Moxham J: Potentiation of diaphragmatic twitch after voluntary contraction in normal subjects. Thorax 1994, 49:1234-1237.

25. Rabe KF, Hurd S, Anzueto A, Barnes PJ, Buist SA, Calverley P, Fukuchi Y, Jenkins C, Rodriguez-Roisin R, van Weel C, Zielinski J: Global Strategy for the Diagnosis, Management, and Prevention of Chronic Obstructive Pulmonary Disease: GOLD Executive Summary. Am J Respir Crit Care Med 2007, 176:532-555

26. Hopkinson NS, Man WD, Dayer MJ, Ross ET, Nickol AH, Hart N, Moxham J, Polkey Ml: Acute effect of oral steroids on muscle function in chronic obstructive pulmonary disease. Eur Respir J 2004, 24:137-142.

27. Steiner MC, Barton RL, Singh SJ, Morgan MD: Bedside methods versus dual energy X-ray absorptiometry for body composition measurement in COPD. Eur Respir J 2002, 19:626-631.

28. Baydur A, Pangiotis K, Behrakis K, Zin W, Milic-Emili J: A simple method of assessing the validity of the esophageal balloon technique. Am Rev Respir Dis 1982, 126:788-791.

29. Wilson SH, Cooke NT, Edwards RH, Spiro SG: Predicted normal values for maximal respiratory pressures in caucasian adults and children. Thorax 1984, 39:535-538. 
30. Miller JM, Moxham J, Green M: The maximal sniff in the assessment of diaphragm function in man. Clin Sci (Lond) 1985, 69:91-96.

31. Man WD, Hopkinson NS, Harraf F, Nikoletou D, Polkey MI, Moxham J: Abdominal muscle and quadriceps strength in chronic obstructive pulmonary disease. Thorax 2005, 60:718-722.

32. Mills GH, Kyroussis D, Hamnegard CH, Polkey MI, Green M, Moxham J: Bilateral magnetic stimulation of the phrenic nerves from an anterolateral approach. Am J Respir Crit Care Med 1996, 154:1099-1105.

33. Stubbing DG, Pengelly LD, Morse $J$, Jones NL: Pulmonary mechanics during exercise in subjects with chronic airflow obstruction. J Appl Physiol 1980, 49:511-515.

34. Duranti R, Filippelli M, Bianchi R, Romagnoli I, Pellegrino R, Brusasco V, Scano G: Inspiratory Capacity and Decrease in Lung Hyperinflation With Albuterol in COPD. Chest 2002, 122:2009-2014.

35. Roussos C, Fixley M, Gross D, Macklem PT: Fatigue of inspiratory muscles and their synergic behavior. J Appl Physiol 1979, 46:897-904.

36. Taylor BJ, Romer LM: Effect of expiratory muscle fatigue on exercise tolerance and locomotor muscle fatigue in healthy humans. J Appl Physiol 2008, 104:1442-1451.

37. Verges S, Sager Y, Erni C, Spengler CM: Expiratory muscle fatigue impairs exercise performance. Eur J Appl Physiol 2007, 101:225-232.

38. Ewig JM, Griscom NT, Wohl ME: The effect of the absence of abdominal muscles on pulmonary function and exercise. Am J Respir Crit Care Med 1996, 153:1314-1321

39. Suzuki J, Tanaka R, Yan S, Chen R, Macklem PT, Kayser B: Assessment of abdominal muscle contractility, strength, and fatigue. Am J Respir Crit Care Med 1999, 159:1052-1060.

40. Derchak PA, Sheel AW, Morgan BJ, Dempsey JA: Effects of expiratory muscle work on muscle sympathetic nerve activity. J Appl Physiol 2002, 92:1539-1552.

41. Engelen MP, Schols AM, Baken WC, Wesseling GJ, Wouters EF: Nutritional depletion in relation to respiratory and peripheral skeletal muscle function in out-patients with COPD. Eur Respir J 1994, 7:1793-1797.

42. Caron MA, Debigare R, Dekhuijzen PNR, Maltais F: Comparative Assessment of the Quadriceps and the Diaphragm in Patients with COPD. J Appl Physiol 2009, 00194.02009.

43. Johnson MA, Polgar J, Weightman D, Appleton D: Data on the distribution of fibre types in thirty-six human muscles: An autopsy study. Journal of the Neurological Sciences 1973, 18:111-129.

44. Stubbing DG, Pengelly LD, Morse $J$, Jones NL: Pulmonary mechanics during exercise in normal males. J App/ Physiol 1980, 49:506-510.

45. Polkey MI, Kyroussis D, Hamnegard CH, Mills GH, Green M, Moxham J: Diaphragm strength in chronic obstructive pulmonary disease. Am J Respir Crit Care Med 1996, 154:1310-1317.

46. Man WD, Luo YM, Mustfa N, Rafferty GF, Glerant JC, Polkey MI, Moxham J: Postprandial effects on twitch transdiaphragmatic pressure. Eur Respir J 2002, 20:577-580.

47. Watson AC, Hughes PD, Louise Harris M, Hart N, Ware RJ, Wendon J, Green M, Moxham J: Measurement of twitch transdiaphragmatic, esophageal, and endotracheal tube pressure with bilateral anterolateral magnetic phrenic nerve stimulation in patients in the intensive care unit. Crit Care Med 2001, 29:1325-1331.

48. Guleria R, Lyall R, Hart N, Harris ML, Hamnegard CH, Green M, Moxham J, Polkey Ml: Central fatigue of the diaphragm and quadriceps during incremental loading. Lung 2002, 180:1-13.

49. Luo YM, Lyall RA, Lou Harris M, Rafferty GF, Polkey MI, Moxham J: Quantification of the Esophageal Diaphragm Electromyogram with Magnetic Phrenic Nerve Stimulation. Am J Respir Crit Care Med 1999, 160:1629-1634

50. Mador MJ, Khan S, Kufel TJ: Bilateral Anterolateral Magnetic Stimulation of the Phrenic Nerves Can Detect Diaphragmatic Fatigue. Chest 2002, 121:452-458.

51. Kufel TJ, Pineda LA, Mador MJ: Comparison of potentiated and unpotentiated twitches as an index of muscle fatigue. Muscle \& Nerve 2002, 25:438-444.

52. Laghi F, Topeli A, Tobin MJ: Does resistive loading decrease diaphragmatic contractility before task failure?. J Appl Physiol 1998, 85:1103-1112.

53. Polkey MI, Luo Y, Guleria R, Hamnegard CH, Green M, Moxham J: Functional magnetic stimulation of the abdominal muscles in humans. Am J Respir Crit Care Med 1999, 160:513-522. doi:10.1186/1465-9921-11-15

Cite this article as: Hopkinson et al:: Abdominal muscle fatigue

following exercise in chronic obstructive pulmonary disease. Respiratory

Research 2010 11:15.

\section{Submit your next manuscript to BioMed Central and take full advantage of:}

- Convenient online submission

- Thorough peer review

- No space constraints or color figure charges

- Immediate publication on acceptance

- Inclusion in PubMed, CAS, Scopus and Google Scholar

- Research which is freely available for redistribution
Ciomed Central 